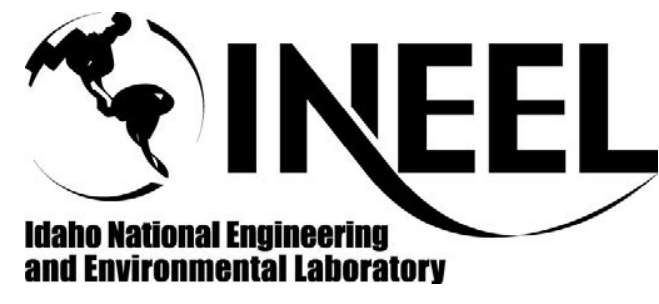

Idaho National Engineoring

and Environmental Laboratory

\section{INEEL/CON-01-00344 \\ PREPRINT}

Science and Technology Roadmapping to Support Project Planning

\author{
Jeremiah J. McCarthy \\ Daniel J. Haley \\ Brent W. Dixon
}

July 29, 2001
Portland International Conference on Management of Engineering and Technology (PICMET ’01)

This is a preprint of a paper intended for publication in a journal or proceedings. Since changes may be made before publication, this preprint should not be cited or reproduced without permission of the author.

This document was prepared as an account of work sponsored by an agency of the United States Government. Neither the United States Government nor any agency thereof, or any of their employees, makes any warranty, expressed or implied, or assumes any legal liability or responsibility for any third party's use, or the results

of such use, of any information, apparatus, product or process disclosed in this report, or represents that its use by such third party would not infringe privately owned rights. The views expressed in this paper are not necessarily those of the U.S. Government or the sponsoring agency. 


\title{
Science and Technology Roadmapping to Support Project Planning
}

\author{
Jeremiah J. McCarthy, Daniel J. Haley, and Brent. W. Dixon \\ Idaho National Engineering and Environmental Laboratory \\ P.O. Box 1625 \\ Idaho Falls, ID 83415-3760 USA
}

\begin{abstract}
Disciplined science and technology roadmapping provides a framework to coordinate research and development activities with project objectives. This case-history paper describes initial project technology needs identification, assessment and $R \& D$ ranking activities supporting characterization of 781 waste tanks requiring a 'hazardous waste determination' or 'verification of empty' decision to meet an Idaho state Voluntary Consent Order.
\end{abstract}

\section{INTRODUCTION}

This paper is a case history of the application of science and technology roadmapping as a key projectplanning tool. Roadmapping is a planning process to help identify technical capabilities needed for a project, map them into technology alternatives, and develop project plans to ensure that the required technologies will be available when needed. The roadmap provides a framework to coordinate applied research and development efforts with operational requirements and schedules.

The specific application discussed is project planning for the evaluation of hundreds of mostly retired process tanks and equipment to determine the locations, amounts, and characteristics of residual hazardous wastes. A wide range of tank sizes, past uses, physical access restrictions, and regulatory requirements presented a number of evaluation process uncertainties requiring systematic resolution.

The case history walks the reader through the process used, indicating identification of the need to roadmap, tailoring of the general roadmapping process for the specific application, intermediate products, midcourse issues and corrections and final results obtained. The intent is to demonstrate the utility of roadmapping for addressing complex technical issues and integrating R\&D activities into general project plans.

\section{A. INEEL Overview [5]}

The Idaho National Engineering and Environmental Laboratory (INEEL) is a U.S. multiprogram laboratory that supports the Department of Energy's (DOE) missions and business lines of environmental quality, energy resources, science and technology and national security. Established in 1949 as the National Reactor Testing Station, the INEEL was once the site of the world's largest concentration of nuclear reactors. Fifty-two test reactors were designed for nuclear propulsion, materials testing, production of medical and industrial isotopes, and power generation. Of these, three are still operating. The INEEL Site is 32 miles west of Idaho Falls, Idaho, on an 890 square mile government reservation. Other INEEL facilities are in Idaho Falls.

The Laboratory employs about 8000 people at eight major applied engineering, interim storage and research and development $(\mathrm{R} \& \mathrm{D})$ facilities. Its vision is to be an enduring national resource that delivers science and engineered solutions to the world's environmental, energy and security challenges. Among other major activities, INEEL is the DOE lead laboratory in the critically important areas of environmental management and nuclear power generation research.

\section{B. INEEL Environmental Management Objectives [7]}

The INEEL's environmental efforts are aligned with DOE's Environmental Management (EM) Program. In particular, INEEL takes an applied science and engineering approach to remediation (clean up) of its legacy hazardous and radioactive wastes generated on the site during its reactor testing era. The INEEL has five objectives to achieve its Environmental Quality vision: 
1. Improve the science that underpins DOE's EM Program

2. Improve integration of Operations and R\&D

3. Provide leadership for establishing a science and technology program in long-term stewardship

4. Develop, demonstrate, and deploy innovative technologies that improve EM Program performance

5. Leverage the expertise and technology developed to solve additional DOE complex environmental problems

\section{Science and Technology Roadmapping [8]}

One means to achieve INEEL's second objective of integrating Operations and R\&D is to develop science and technology (S\&T) roadmaps. Technology roadmaps identify specific technology requirements (needs), describe the current state of applicable technology, evaluate options, and portray a technology development life cycle plan that complements requirements. These roadmaps - designed to support the needs of a program or (in this case) a specific project - can provide a framework to plan and coordinate applied research and development efforts with operational requirements. Thus they also contribute to the fourth objective, development and deployment, in that their goal is to utilize innovative technologies to improve baseline performance of remediation operations. And, they help meet INEEL's first objective, improving EM science underpinnings, by applying science-based innovative solutions to site operational needs. (Information on a number of EM roadmaps and copious references for DOE and industry roadmaps can be found at the web site listed in [8].)

The S\&T roadmapping process has four phases. The first phase, roadmap initiation, is preparation for the actual roadmapping process. The second phase is the operational needs assessment phase and is the most important phase of the roadmapping effort. The third phase addresses technical response development. At this point, the focus shifts from the remediation operations community to the R\&D community. In the fourth and final phase, the roadmap report detailing the desirable technical options available and any additional $R \& D$ if necessary is reviewed and released for implementation. The roadmap report provides the basis for applied R\&D budgets and project work planning. Fig. 1 shows the primary steps and products of each phase.

Only three of the four roadmapping phases are detailed in the case history described below. The cost and schedule roadmapping details and subsequent implementation (phase four) of application-specific technologies selected were accomplished in late 2000 and early 2001.

\section{PURPOSE}

This paper describes the process used by the INEEL to develop an applied engineering and research roadmap document that identifies potentially useful technologies or technology gaps that need to be addressed to successfully characterize contents of its storage tanks and certain equipment.

Roadmapping applies collaborative realism and builds consensus between Operations and R\&D about technology development. The benefits of any specific roadmapping effort are measured by one or more common parameters such as reduction in life-cycle costs, reduction in programmatic or project technical risks, reduction in risks to human health and the environment, as well as an increase in research program relevancy.

\section{VOLUNTARY CONSENT ORDER AND ROADMAPPING}

In 1996, the INEEL began negotiations with the State of Idaho Department of Environmental Quality (IDEQ) to address various noncompliance issues regarding Resource Conservation and Recovery Act (RCRA) hazardous waste regulations. These negotiations culminated in June 2000 with a Voluntary Consent Order (VCO) that specified numerous actions and milestones that would enable the INEEL to come into regulatory compliance in an orderly fashion. [4] 


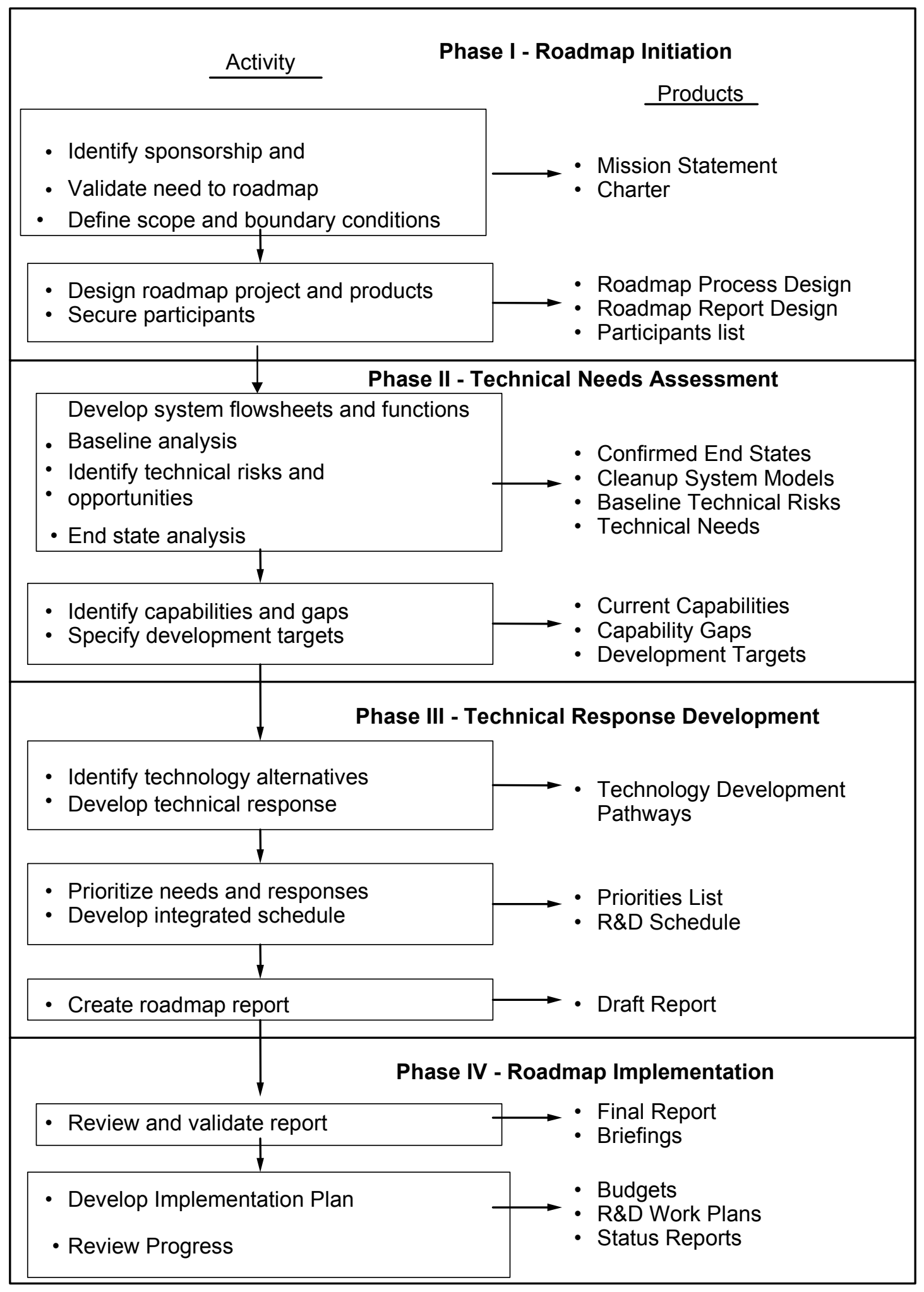

Fig. 1. Roadmapping Process and Products.

Among other actions, the VCO specifically requires the INEEL to complete hazardous waste determinations for itemized tank systems including many underground tanks in accordance with RCRA requirements [2] and 
supporting State of Idaho regulations [3]. Material in more than 700 tanks, various unused equipment, and legacy samples needs to be characterized. Empty process or product tanks need to be verified to be empty. In some cases the work is expected to be straightforward, for example, sampling and analyzing the contents of a water softener. In other cases, tanks contain hazardous and radioactive (mixed) waste and are located among other vessels in a maze of piping within inaccessible radiological hot cells. The entire process - determination of tank contents or verification of empty - is termed "VCO tank characterization" in this paper.

Personnel within Operations and $\mathrm{R} \& \mathrm{D}$ recognized the need to consider innovative technological solutions to some of the more intractable VCO tank characterization problems. Operating in a safe and cost effective manner is paramount at INEEL. It was recognized that alternative (compared to baseline) technologies applied to certain difficult-to-characterize tanks had the potential to reduce personnel and environmental risk and project savings in time and resources. As a result a small VCO roadmap team consisting of the VCO tank characterization project engineer, three $R \& D$ engineers and a roadmapping process advisor was formed. Support staff included workshop facilitators and database personnel.

Because of time constraints - 3 months to the end of the Fiscal Year (FY) - it was decided that the roadmapping effort would include all essential elements of project roadmapping except specific economic considerations and an implementation strategy, details of which would be deferred to the next FY. Nonetheless, an approach to accomplish future implementation would be outlined in a Path Forward report section.

The science and technology roadmap effort supporting the VCO characterization project had goals to:

- Identify technologies or capabilities that can support VCO tank and certain equipment characterization needs

- Identify existing technologies that need little modification to be readily usable for tank characterization

- Identify existing technologies that need major modification or development and therefore need to be addressed expeditiously if chosen

- Identify characterization needs that do not currently have a technical solution (technology gaps)

\section{VCO TANK CHARACTERIZATION NEEDS}

Identification of operational needs for VCO tank characterization was conducted in a two-step process. The first step was to familiarize the VCO roadmap team with tank characterization requirements. R\&D members of the VCO roadmap team also spent time gaining an appreciation for what constituted "VCO tank systems". These systems include over 700 active waste tanks, inactive waste tanks, inactive process or product tanks and any attached piping or other devices in addition to the tank contents. The second step was to provide a facilitated workshop to enable VCO tank characterization Operations personnel to actively participate in the technology needs identification process.

Key VCO tank characterization Operations personnel were invited to participate with the VCO roadmap team in a facilitated workshop. The rhetorical question, "What keeps you from characterizing your tanks?" was presented. Operations personnel listed problems they had, or expected to encounter, when characterizing the VCO tanks they were responsible for. An unstructured list of 93 items consisting of tank characterization work functions or associated technical issues that inhibited characterization resulted. Flowcharts sequencing the general baseline VCO work functions were next assessed, discussed and revised as needed to ensure all present were in agreement about the characterization processes. An exercise was conducted to place each problem item on the list some place (or places) on the flowcharts. In this manner the veracity and usefulness of the flowcharts and the 93 items were ascertained. The revised flowcharts are shown in Figs. 2, 3, and 4.

After all items were discussed, summarized or categorized, each operations person was asked to rank the work functions and associated technical issues from most troublesome to least troublesome. The results of the meeting were believed to well represent prioritized VCO tank characterization 'needs' that might benefit from technology assistance.

After the initial workshop, follow-up meetings were held with key operations persons responsible for tank characterization work. The purpose of these visits was to glean additional details on specific problems and needs 
that could be applied to the VCO roadmap. An issues versus function matrix ranked from most troublesome function to least troublesome function was fashioned to summarize what was learned from the workshop and these follow-up meetings (Fig. 5).

Fig. 5 shows that Get A Representative Sample ranked number one on the list of operational concerns. Operations personnel were particularly troubled by their inability to obtain a sample for characterization from some of the difficult or dangerous and also meet EPA sampling and analytical requirements. Sample Content or Residue (ranked 6) and Analyze the Sample (ranked 8) had similar sampling concerns.

\section{Basic Process}

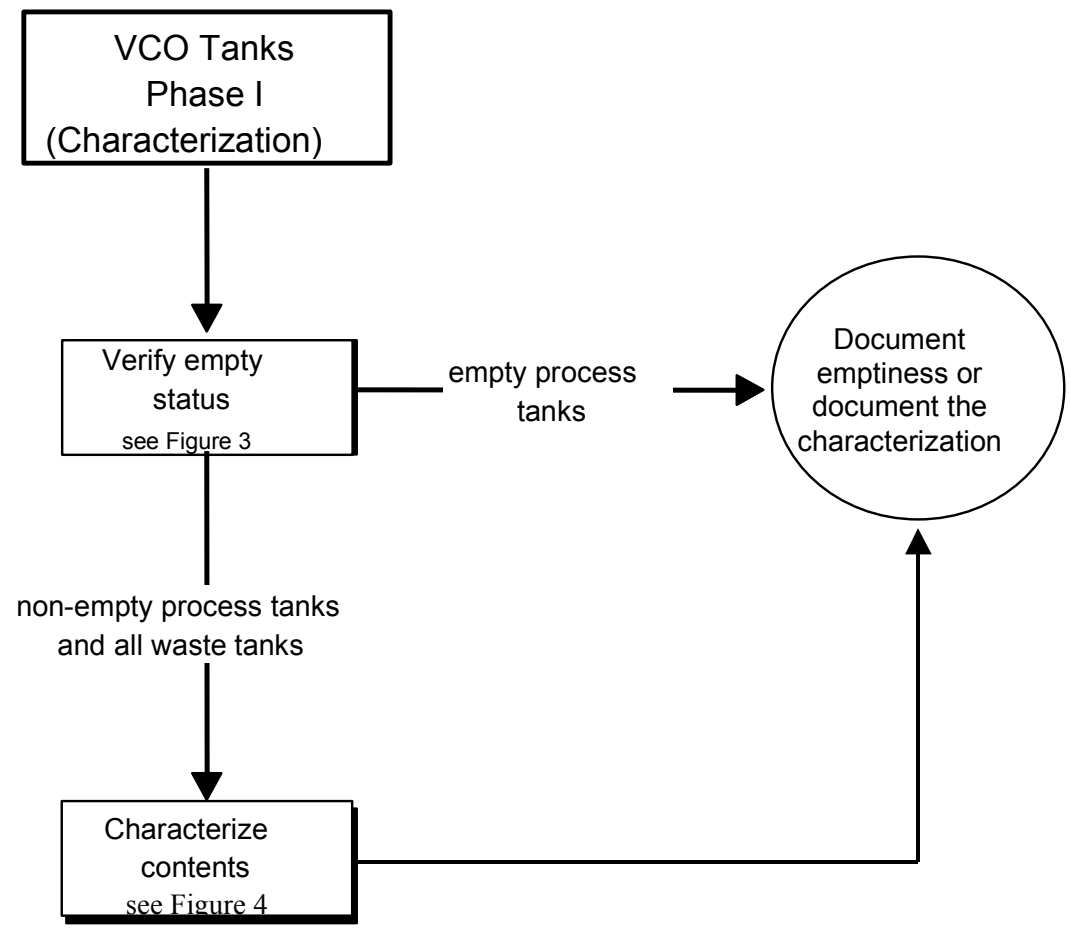

Fig. 2. General VCO Tank Characterization Process 


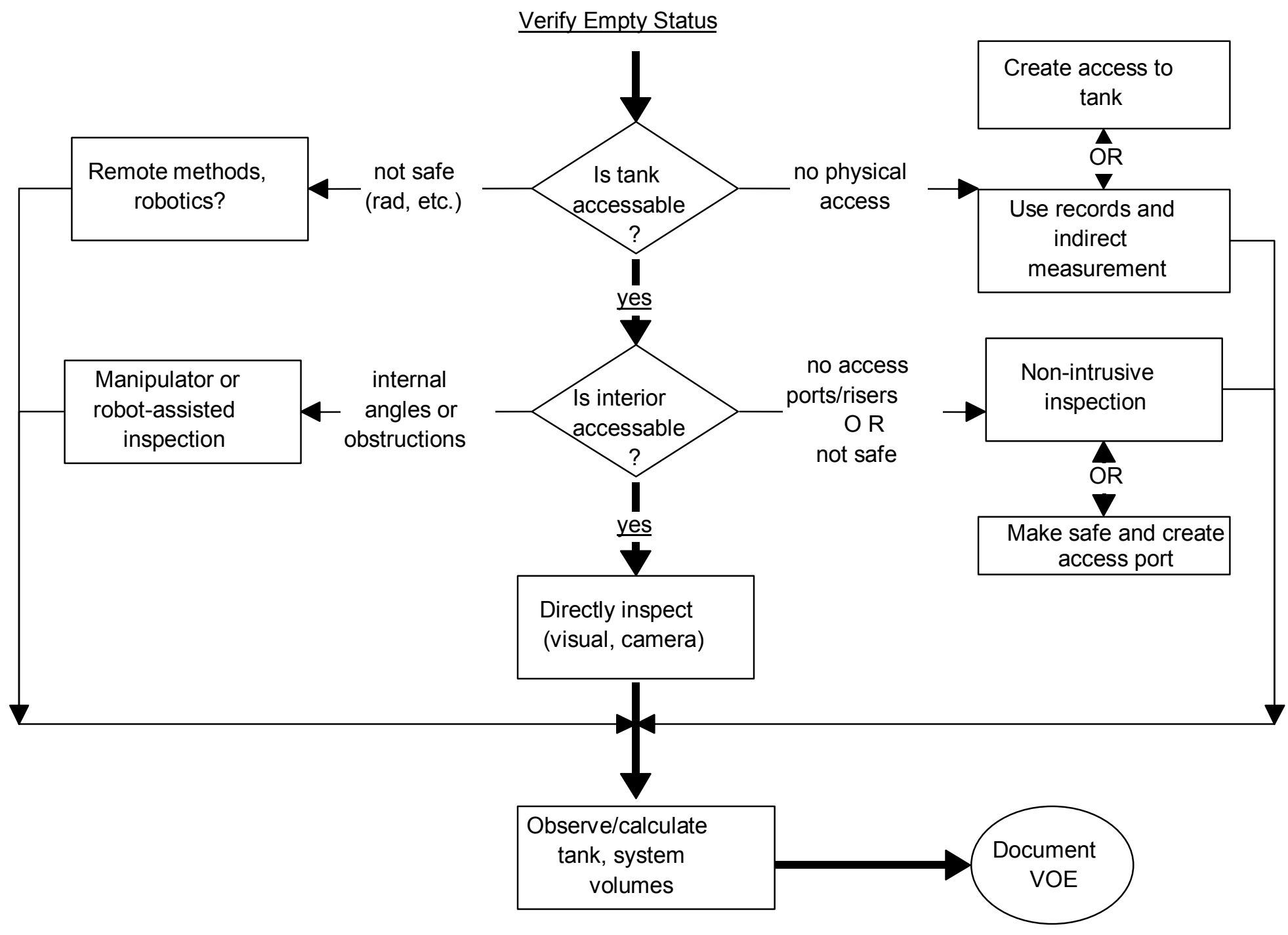

Fig. 3. VCO Tank Verification of Empty Process 


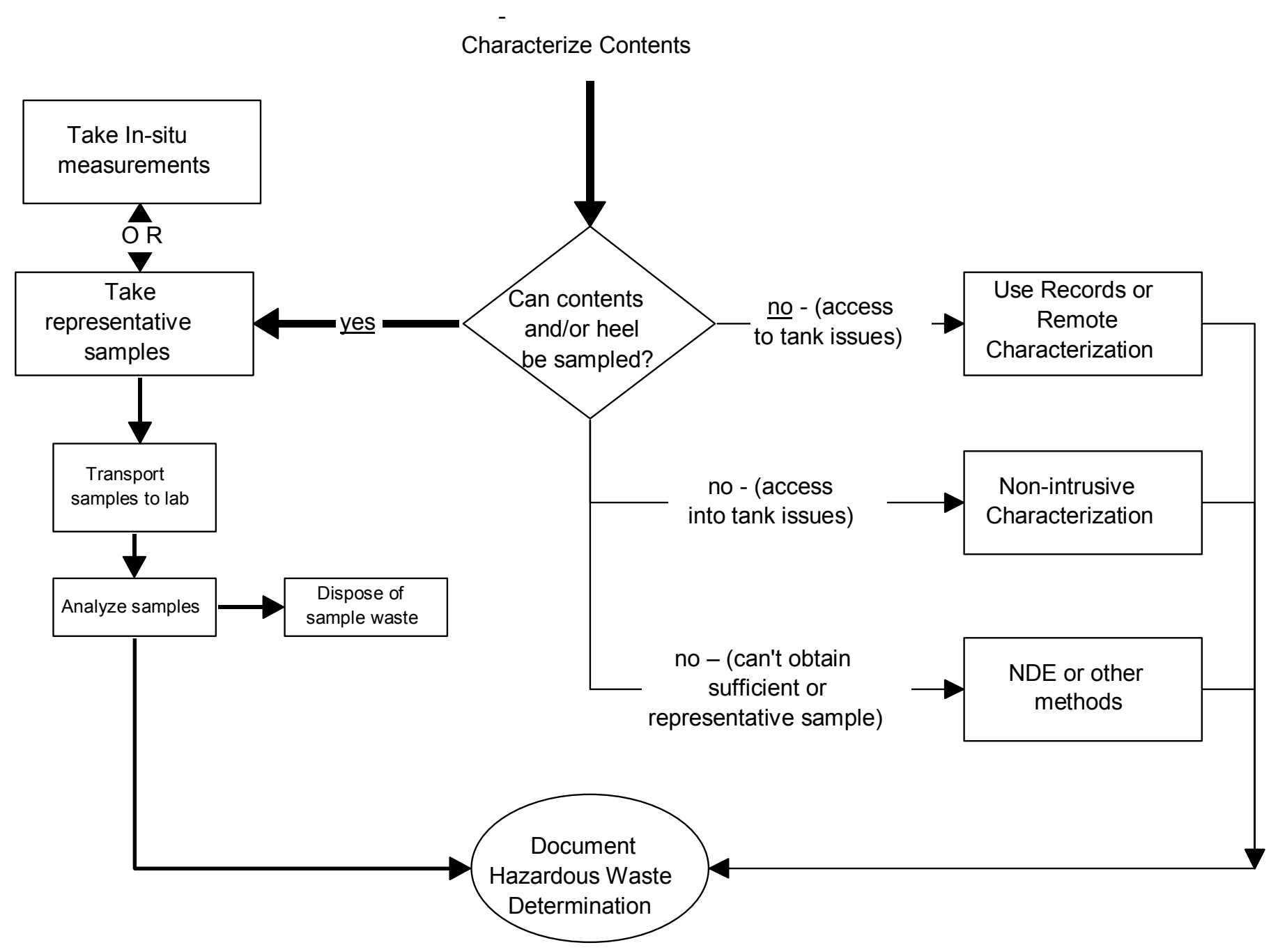

Fig. 4. VCO Tank Hazardous Waste Determination Process 


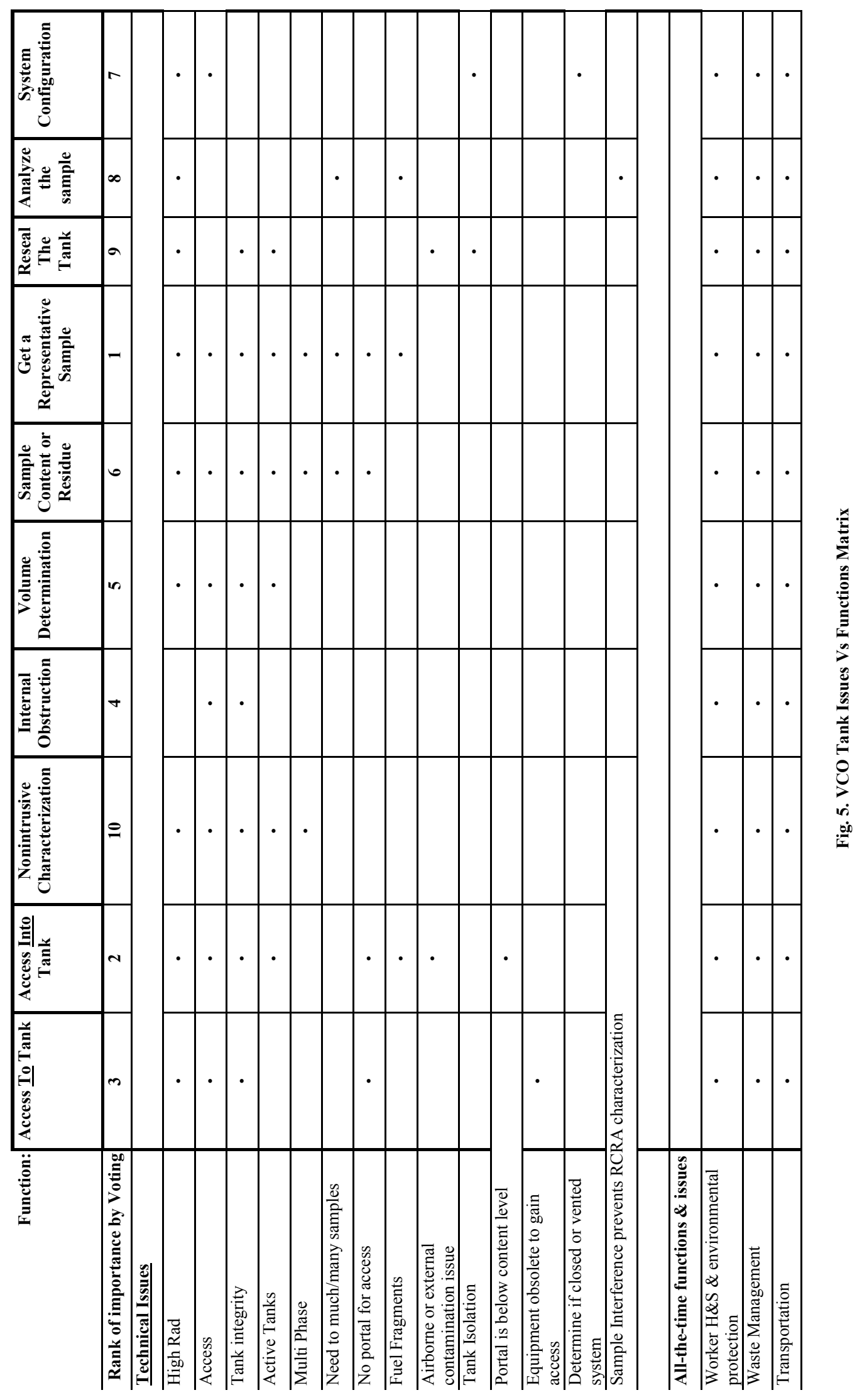


Access into the Tank was the second ranked potentially troublesome function. Physical restrictions, obstructions, sample hatch locations, tank riser unknowns, the opportunity to sample 'active' tanks and integrity of the tank system were common issues noted. Internal Obstructions (ranked 4) had similar concerns.

Physical Access to the Tank ranked number three. Without physical access, the opportunity for successful representative sampling, verification of empty or Nonintrusive Characterization (ranked 10) is small to none.

Tank and content Volume Determination ranked number five. Volume determination is important not only to determine the magnitude and toxicity of the waste contents but also for verification of empty determinations. Issues noted about volume determination difficulties were similar to those noted about access into the tank.

Determination of System Configuration, which includes all associated piping, valving and other devices associated with the "tank system" ranked number seven. There was little confidence in as-built drawings for some of the older tank systems.

Potential difficulties with Reseal the Tank ranked number nine. Concerns had to do primarily with environmental contamination and tank integrity, especially when resealing an active tank system on the VCO tank list.

Finally, there were certain overarching "all-the-time" issues for all work functions. Worker Health and

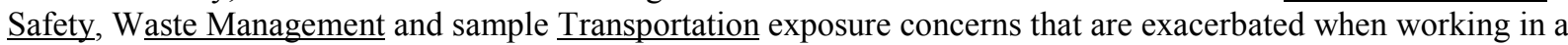
radiological environment were noted repeatedly.

A majority of the characterization work under the VCO focused on defining tank system contents or the contents of other tank-like items (such as sumps). However there were some characterization requirements for oneof-a kind non-tank equipment items. Technology gaps were identified in these cases.

\section{ALTERNATIVE TECHNOLOGY IDENTIFICATION AND ASSESSMENT}

Once the VCO tank characterization work functions and their associated troublesome technical issues were understood, the VCO roadmap team sought promising technologies that could potentially mitigate or meet the needs identified. An existing technology review was conducted. The internet, the INEEL technical library, and DOE, Department of Defense, Environmental Protection Agency and Thomas Register (American Manufacture Products) databases were the principal sources of information. Fig. 5 and the earlier workshop proceedings provided the basis to guide selection of candidate alternative (compared to baseline) technologies that could be considered potentially useful.

In-house Subject Matter Experts (SME) were used as much as practicable as informal sounding boards and literature information sources. SME expertise encompassed process measurement, nondestructive evaluation, decontamination and decommissioning, chemistry, robotics, and tank focus specialties. SMEs were later utilized more formally at the subsequent technology validation workshop.

Technical maturity of the candidate technologies was an important factor when considering the technology availability for the VCO tank application because all tanks have to be characterized by September 30, 2006. A high maturity rating was given to technologies that were directly applicable to and relatively available for a VCO work function. These included technologies that were commercial or available off-the-shelf as well as technologies that had been applied in similar situations within the federal system. A medium maturity rating was given to technologies that showed probable applicability to the work functions but had not been directly demonstrated. Such technologies typically were believed to require an additional 1 to 2 years of testing and demonstration before they could be applied to the VCO characterization problem. A low maturity ranking was given to those technologies that showed possible applicability but would likely be available for implementation only after 3 or more years of testing and demonstration.

Technologies identified for assessment that could have direct application to VCO tank characterization were consolidated into a common alternative technologies database that mapped them directly to the relevant work 
functions and technical issues. Those that had a high maturity and were determined to be superior to or as good as the baseline work functions were catalogued for further consideration. Those technologies determined to be less capable than the baseline work functions were dropped from active consideration but maintained in the database.

\section{VALIDATING THE VCO NEEDS - ALTERNATIVE TECHNOLOGY CONNECTION}

A second facilitated workshop was used to validate the matching of identified needs and technologies. An 'Alternative Technologies Report' summarizing over 40 of the most promising technologies from the parent alternative technologies database was provided to all participants. The Report gave the alternative technology name, reference, point of contact, the work function(s) it was designed to accomplish and a 50 to 100 word description. The goal of the workshop was to determine, through discussion and voting, how well these technologies mitigated the troublesome technical issues associated with the various VCO characterization work functions. The workshop included both SMEs and Operations personnel participants.

Meeting participants, led by operations personnel, came to a consensus about the baseline technologies or methods they would likely use to accomplish their work functions given no alternatives. This baseline was used for comparison to evaluate the merits of the alternative technologies. The baseline technologies by work function are in Table 1.

Table 1. Baseline Technologies

\begin{tabular}{|l|l|}
\hline \multicolumn{1}{|c|}{ Work Function } & \multicolumn{1}{c|}{ Baseline Technology or Method } \\
\hline Access to the Tank & $\begin{array}{l}\text { Equipment/tool/sensor/camera on a "flexible stick" } \\
\text { Portable shielding } \\
\text { Interrupt facility operations to get to tank }\end{array}$ \\
\hline Access into the Tank & $\begin{array}{l}\text { Disconnect flange } \\
\text { Go through existing piping or manway } \\
\text { Cut hole in tank and repair }\end{array}$ \\
\hline Nonintrusive Characterization & $\begin{array}{l}\text { No existing baseline technology or method } \\
\text { Internal Obstructions }\end{array}$ \\
\hline Volume Determination & $\begin{array}{l}\text { Physically viewing } \\
\text { Dipstick ("rock on a rope") } \\
\text { Process knowledge and calculation } \\
\text { Open bottom to see if something comes out } \\
\text { Electrical probe } \\
\text { Sight glass }\end{array}$ \\
\hline Sample Content or Residue and & $\begin{array}{l}\text { Scoop or swipe on a stick } \\
\text { Collecting a sample out of a sample port or by turning a } \\
\text { valve } \\
\text { COLIWASA sampler (liquid) } \\
\text { Manual extraction } \\
\text { Process knowledge }\end{array}$ \\
\hline $\begin{array}{l}\text { Threaded cap } \\
\text { Weld it shut }\end{array}$ \\
\hline
\end{tabular}




\begin{tabular}{|l|l|}
\hline Analyze the Sample & EPA-specified analysis by on-site or off-site analysis \\
\hline System Configuration & Drawings \\
& Process knowledge \\
& Photography \\
& Physically viewing \\
\hline
\end{tabular}

Voting members who had a stakeholder interest in technology-needs issues were identified. Four INEEL site Operations representatives and five R\&D Subject Matter Expert representatives were selected to vote. VCO roadmap team members did not vote but did participate in the discussion. Operations representatives had a practical viewpoint and rated alternative technologies with respect to their usefulness or desirability to mitigate the troublesome characterization issues affecting their particular tanks. SME voters had a more applied science-based viewpoint including experience with some of the alternative technologies and rated them with respect to their potential to do the job. Rating was qualitative: the alternative technology was expected to work better than, the same as, or not as well as the baseline technology; or the technology was not expected to meet the need at all. The meeting facilitator later assigned prescribed scoring numbers to each qualitative rating so that the results could be evaluated and compared.

During the workshop, there was considerable discussion about RCRA-prescribed analytical methods versus unofficial screening methods, and statistical sampling requirements versus indirect measurements. This discussion was driven by health and safety concerns of operational personnel about characterizing mixed (hazardous and radioactive) waste. Several new alternative technologies that could help mitigate such concerns were introduced by the SME at the workshop. A few other technologies previously identified by the VCO roadmap team were dropped from consideration. The principal reasons were that they were 'services' and not 'technologies', or that through round-table discussion, the participants determined they were misplaced. The group discussion also identified apparent technology gaps when it was concluded that none of the alternative technologies identified satisfied a tank or equipment characterization need.

\section{VCO ALTERNATIVE TECHNOLOGY ASSESSMENTS}

As a result of its technology review, two workshop discussions, technology rating scores, supplementary information, Subject Matter Expert input and engineering judgement, the VCO roadmap team was able to fashion a roadmap report discussing and ranking the merits of promising alternative technologies for VCO tank characterization. [1]. The core of the report was organized into specific work function sections (the columns of Fig. 5) that discussed relevant alternative technology applicability and maturity. Each section described the work function and discussed merits of the baseline technology, the relevant alternative technology (including technology gaps), and presented conclusions and recommendations about the most desirable alternative technologies choices. Each section also contained a useful Alternative Technology Rating Results Table evaluating all alternative technologies that were rated better than or same as baseline technologies to do the work. Technologies that were rated lower were simply listed after the table. In any case, all technologies were described in a finalized 'Alternative Technologies Report ' appendix.

While the details about the description and merit scores of specific alternative technologies are beyond the scope of this paper, a summary of some general types of alternative technologies applicable to VCO characterization is in Table 2 and a listing of major technology gaps identified is in Table 3.

The alternative technology assessments indicated that while there were many solutions to VCO characterization problems, there remained a variety of problems without adequate solutions. Fig. 6, using an issuefunction interface, summarizes where technologies appear to need maturation, where they are ready for use or where a technical solution is not yet apparent. 
Various Tank Cutting Technologies - a suite of mature tools that cut away obstructions using various types of saws, drills, nibblers and other specialty power tools (essentially baseline);

Pipe Crawlers/Explorers - various tethered robots that can carry non-destructive examination equipment, sensors, grippers or cameras in pipes;

Non-destructive Examination Technologies (NDE) - technologies based on radiation physics, x-ray technology, sound waves, or focused light beams to indirectly characterize tank contents or liquid levels. INEEL has developed mature and fielded technology in this area to assist the U.S. Army's chemical munitions destruction efforts;

Two and three dimensional imaging systems - technology that can give information about tank configuration, volume and contents;

Pipe crimps, pipe cappers, pipe plugs, wall coring tools and tank pneumatic plugs - readily available in the market place (essentially baseline);

Field Portable Spectrophotometers - that use photons to detect areas of radioactive contamination or use ion mass spectrometry to identify separated ions of suspected contaminants;

Fluid Mixers - available technology using fluid pulse jet mixing to resuspend sludge and homogenize its contents for sampling;

Table 3. Selected VCO Characterization Alternative Technology Gaps

Pipe Crawlers/Explorers - that can maneuver in pipes less than 3 inches diameter;

Alternative Sampling and Analysis Protocols - that are acceptable to the regulating agencies for dangerous or difficult sampling situations;

In-the-Field Non-Intrusive Characterization Technologies - that are acceptable to the regulating agencies for tank content characterization in dangerous or difficult sampling situations;

Ultrasound Technology - that is improved to better map internal obstructions in tanks;

Underground Pipe Sensing Technology - for more sensitive underground tank pipe system configuration definition;

Tank Resealing Technologies - for safe and quality resealing of breached tank walls; Faster Radiation Counting Techniques - to rapidly quantify low levels of radioactivity in lead bricks and other equipment. 


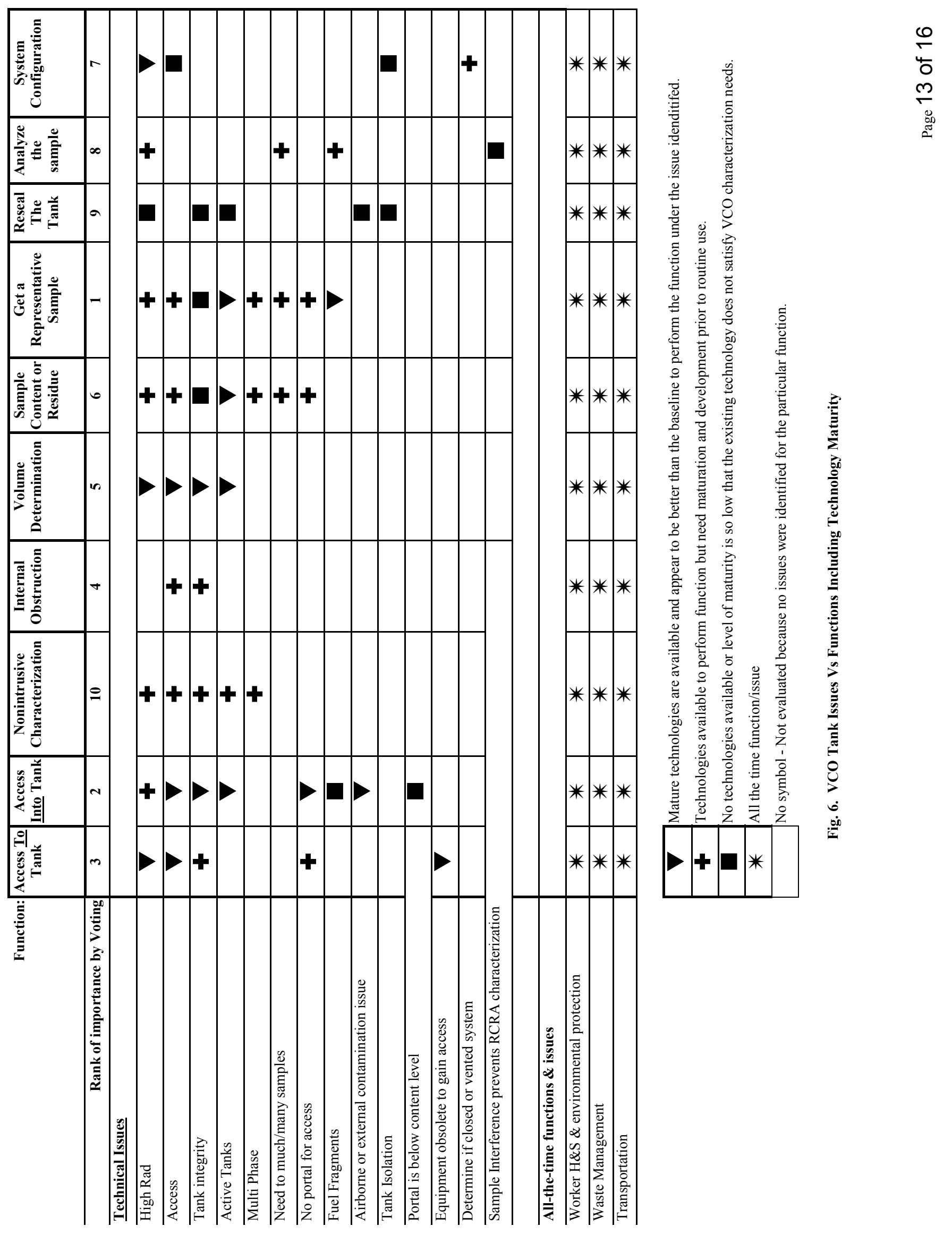




\section{RESULTS}

This science and technology roadmapping process helped integrate applied research and development planning with VCO characterization project requirements. The roadmapping process injected a complementary component that highlighted and ranked the most difficult technical issues that needed timely R\&D attention to help meet the overall VCO deadline. Technology roadmaps represent applied integration of Operations with R\&D.

As a result of the roadmapping effort, six technologies were identified that show significant promise to facilitate tank characterization. Three technologies were found that could assist in the verification of emptiness; those technologies and brief descriptions are listed below.

- Digital Radiography and Computed Tomography - An X-ray radiography technique used to discern the presence of materials in a tank.

- Noncontacting Laser Acoustic Spectrometry - A technique that uses a broadband audible noise to excite a tank. A laser vibrometer measures out-of-plane surface velocity of the tank. Empty tanks have distinctly different acoustic signatures than tanks having liquid contents.

- Contacting Acoustics Resonance Spectrometry - Similar to noncontacting laser acoustic spectrometry except that the excitation horn is directly coupled to the tank.

Three technologies were found that can be uses for the characterization of a tank's contents. Those technologies and a brief description are listed below.

- Portable Isotopic Neutron Spectroscopy (PINS - This technology interrogates the tank with a Californium neutron source and analyzes the resultant gamma-rays emitting from the tank contents. Comparison of the gamma signature with a large library of substances can classify the substance to the elemental level.

- Secondary Ion Mass Spectroscopy (SIMS) - A laboratory-based mass spectrometry technique used to determine if the container or environmental area around the tank has chemical contamination present on surfaces. This technique uses very small quantities of sampled material.

- Ion Mobility Spectrometry (IMS) - A portable mass spectrometry technique used to identify low level chemical vapor contamination in the are near or inside of the tank.

All of these technologies have been extensively used by the US Army and Allied Forces for the detection of chemical warfare agents in munitions.

For the technologies identified through the roadmapping effort, the INEEL is currently conducting a demonstration using mockup-tanks and actual VCO tanks to show the efficacy of these technologies to characterize actual tanks and tank contents. Results are expected by mid-summer 2001. After the data are analyzed, the VCO Project will begin discussions with regulatory agencies to negotiate use of the data for tank characterization. At this time, the data used for verification of a tank's empty status appears to be very supportable. However, the regulatory agencies typically require certified analysis for the characterization of hazardous waste; therefore, it is expected that the PINS, SIMS, and IMS techniques will initially be used as screening tools rather than for definitive analysis. Nevertheless, it is expected that these data will be very useful in reducing analytical costs and reducing worker exposure.

The roadmapping effort also provided detailed "need statements" that are used by the Department of Energy's Site Technology Coordination Group to integrate operational needs with future and on-going research and development. The submission of these need statements has generated considerable interest from the research community. The Idaho National Engineering and Environmental Laboratory need statements can be found on the Internet [6]. Additional information on the Department of Energy Science and Technology Coordination Group can also be found on the Internet [7].

\section{CONCLUSIONS}

Science and technology roadmapping is a focused procedure for developing defensible technical solutions by: 1) defining what technical requirements need to be addressed and how, 2) identifying potential alternatives (or 
noting gaps) that can satisfy those requirements, 3) evaluating and ranking the alternatives, and then 4) fashioning a report with the results and an integrated schedule to implement and verify the most desirable options for the program or project. In essence, this roadmap process represents a particular application of the systems engineering process.

The VCO roadmap report provided the justification and information to support a more realistic means to accomplish VCO tank characterization objectives. A detailed "path forward" summarizing future specific actions needed to evaluate and deploy desirable alternative technologies was included in the roadmap report.

Identification and ranking of VCO work functions and identification of alternative technologies (or lack of them) that can potentially mitigate troublesome characterization issues have benefited both R\&D and Operations. Alternative technology that can help accomplish the work can be evaluated and implemented. Technology gaps that need to be addressed can be researched.

The VCO roadmap report, as issued for this effort, provided only partial information necessary for timely resolution of end user needs [1]. While promising alternative technologies were identified, described and ranked (in general), a site-specific technology/tank implementation and verification plan remains the final step for roadmapping completion (phase 4).

Site-specific tanks or tank systems have to be chosen to determine if a clear characterization path forward exists in their case and which alternative technologies identified can expedite work. Benefit/cost decisions specific to the situation have to be made to decide which potential alternative technology is most desirable in terms of less cost, time, resources or increased safety compared to the baseline. Next, budgets have to be allocated and scheduling plans have to be made to engineer and apply the alternative technology to meet the tank-specific requirements. R\&D and operational schedules have to be integrated to ensure that timely deployment and verification of the chosen technology will happen within VCO time deadlines.

As this paper is written, the VCO roadmap report is being reviewed and such decisions are being made. Depending on the extent of funding, implementation plans will be developed, budgets allocated, and integrated work plans executed for selected alternative technology deployment that will support safe and efficient VCO tank characterization at the INEEL.

\section{REFERENCES}

1. Bates, S.O., et al., Voluntary Consent Order Tank and Equipment Characterization Technology Roadmap, Idaho National Engineering and Environmental Laboratory Report INEEL/EXT-200-01218, September 2000

2. Code of Federal Regulations 40 CFR 262, "Standards Applicable to Generators of Hazardous Wastes," Federal Register, July 1, 1999.

3. Idaho Administrative Procedures Act IDAPA 58.01.05, "Rules and Standards of Waste," Idaho Department of Environmental Quality Rules

4. Idaho Department of Environmental Quality, B.R. Monson, IDEQ to D.N. Rasch, DOE-ID, Enclosure: "Consent Order, "Idaho Code, Section 39-4413, June 13, 2000

5. Idaho National Engineering and Environmental Laboratory, Public Affairs Department, INEEL Overview 2000

6. Idaho National Engineering and Environmental Laboratory Site Technology Coordination Group http://stcgneeds.inel.gov/index.htm

7. Idaho National Engineering and Environmental Laboratory, Institutional Plan FY 2001-2005 http://www.inel.gov/documents/ip2001/

8. U.S. Department of Energy Office of Environmental Management, Applying Science and Technology Roadmapping in Environmental Management, Draft, , July 2000 (available at http://emiweb.inel.gov/roadmap.html)

9. United States Department of Energy Office of Science and Technology., Site Technology Coordinating Groups http://ost.em.doe.gov/progstcg.html

This work was supported by the U.S. Department of Energy, Assistant Secretary for Environmental Management, under DOE Idaho Operations Office Contract DE-AC07-99ID13727. 


\section{ABOUT THE AUTHORS:}

Jeremiah J. McCarthy, Ph.D., P.E. is a Consulting Engineer at INEEL with over 30 years experience in engineering research, development and practice. He is a member of the Systems Sciences and Engineering Department whose mission is to develop and apply science-based systems and decision analysis capabilities resulting in successful projects and effective, defensible decisions.

Daniel J. Haley, P.E. is an Advisory Engineer at INEEL with over 20 years of engineering practice, project management and project engineering experience in environmental engineering. Currently, Mr. Haley is coordinating the prioritization of tank characterization efforts for the VCO Program and is conducting a demonstration of the technologies discussed in this paper.

Brent W. Dixon is an Advisory Engineer supporting DOE's Complex-Wide Science and Technology Integration work. He is the technical lead for DOE's Environmental Management science and technology roadmapping methodology development and a process consultant for several ongoing roadmaps. Mr. Dixon has over 20 years experience at INEEL and holds a Bachelor of Science degree in Civil Engineering from the Massachusetts Institute of Technology.

Presented and published at the Portland International Conference on Management of Engineering and Technology (PICMET '01), Portland, OR, USA July 2001 